\title{
LIGHT AND THE IMMATURE VISUAL SYSTEM
}

\author{
JUDITH ROBINSON and ALISTAIR R. FIELDER \\ Birmingham
}

\begin{abstract}
SUMMARY
Preterm neonates are cared for in an environment which is continuously and brightly lit, and is very different to that experienced at any other time of life. The amount of light reaching the neonatal eye is governed by two groups of factors. Physical factors include intensity, spectral characteristics and duration of light exposure. Physiological factors are: Frequency of eyelid opening, transmission of light through the closed eyelid, pupil reactivity and area, transmission by the ocular tissues and retinal surface area. Retinal irradiance declines with increasing postmenstrual age. Mechanisms by which light may affect the neonatal eye and clinical conditions in which light have been implicated are considered.
\end{abstract}

Over the 24 hour period adults are generally exposed to a mixture of natural and artificial light, each with different spectral characteristics. Periods of sleep provide some respite from what would otherwise be continuous exposure to light. The fetus grows in almost complete darkness ${ }^{1}$ whilst the environment in which preterm babies are cared for, the neonatal unit (NNU), is usually brightly and continuously lit. Thus the baby born prematurely is exposed to a pattern of lighting quite different from that experienced either in utero or at any other time of life.

Advances in neonatal medicine, have led to increased survival of the very low birthweight neonate, ${ }^{2}$ and these immature babies are at risk of developing a variety of visual problems ranging from myopia and strabismus, to blindness due to retinopathy of prematurity (ROP). ${ }^{3.4}$ Although some of these conditions such as ROP have been extensively investigated, many issues remain unresolved. That light may be a factor in ROP has been considered for over four decades. ${ }^{4.5 .6 .7 .8 .9 .10}$ Whilst there is little doubt, that in the adult, visible radiation can damage the lens, photoreceptors and retinal pigment epithelium, ${ }^{11,12.13}$ the effect of early exposure to light on the immature visual system is unknown. Furthermore there is little information about either the lighting environment of neonatal units or the biological factors which control the amount of light entering the eye.

Correspondence to: Judith Robinson, PhD, Department of Cellular and Developmental Biology, Harvard University, The Biological Laboratories, 16 Divinity Avenue, Cambridge, MA 02138 USA.
This article is divided into three sections. First, the data on the neonatal light dose is summarised. Second, the mechanisms by which light may affect the eye will be considered and third, we mention clinical conditions in which light has been implicated as a factor.

\section{NEONATAL LIGHT DOSE}

The amount of light reaching the eye is governed by two groups of factors. First, physical factors: the intensity, spectral characteristics, and duration of light exposure. Second, physiological factors: the frequency of eyelid opening, transmission of light through the closed eyelid, pupil reactivity and area, transmission of light through the optic media and calculations of the retinal area on which an image is formed.

\section{PHYSICAL FACTORS}

Neonatal units are illuminated 24 hours a day, typically by a mixture of daylight and fluorescent tubes. Several studies have reported on the light intensity within NNUs but most state only illuminance. ${ }^{14,15,16}$ Illuminance measurements are based on the ability of the optical radiation to induce a sensation of light in the eye, and are weighted by the filtering properties of the adult human eye. Illuminance surveys therefore do not completely describe the lighting conditions in NNUs, particularly at the shorter wavelengths. ${ }^{17}$ Generally, the levels reported range from 400-1000 lux during the day, reducing in those units which have initiated a cyclic lighting regimen, to 50-100 lux at night. In addition, these studies demonstrate that light intensity varies greatly both between and within NNUs, and can be influenced greatly by seasonal factors. The illuminance (brightness) of seven NNUs in the UK has recently been measured over the 24 hour period and except for two low dependency areas, all were brightly and continuously illuminated. ${ }^{15}$ At night when the lighting was provided solely by fluorescent tubes the mean illuminance was 348 lux: range 192-690 lux. During the day the mean illuminance was 470 lux: range 236-905 lux. The high dependency regions in four of the seven units were significantly brighter than their corresponding low dependency nurseries at all times. In two of these units there is a policy of reducing the level of artificial light in 
the low dependency areas at night and under these conditions the minimum illuminance was 50 lux.

There are two studies of the spectral characteristics of NNU lighting. ${ }^{17,18}$ In the latter study multi-point spectral irradiance curves were obtained at each cot or incubator. One conclusion apparent from both investigations was that photometric measurements of NNU lighting, are by themselves inadequate: the NNU irradiance from $400-$ $500 \mathrm{~nm}$ is about $30 \%$ of the total irradiance, in contrast illuminance only accounts for $10 \%$ of its integral. Thus photometric estimates of light exposure underestimate the amount of light reaching the infant, especially at shortwavelengths. Both the irradiance and illuminance surveys showed significant and consistent differences between the high and low dependency regions (Table I), the former being associated with the highest light intensities.

In addition to general ward illumination, infants are exposed to light sources both as part of their treatment and during examinations. Premature infants are often exposed to phototherapy (2400-3000 lux) for the treatment of neonatal jaundice. During phototherapy which may last for periods exceeding 24 hours, infants will generally have their eyes shielded from the phototherapy lights by "patches", which transmit some of the light ${ }^{19,20}$ ranging from $<2-10 \%$ at $700 \mathrm{~nm}$ according to patch type. ${ }^{21}$ Eyeshields securely in place will attentuate $>90 \%$ of the light emitted by a phototherapy source and reduce the potential risks of photokeratitis due to UV exposure and retinal injury mediated through the blue-light photochemical mechanism. However, eyeshields are prone to slip away from the eyes (9292 of 16615 observations). ${ }^{22}$

Routine ophthalmoscopic examinations are performed on neonates of low gestational age to screen for ROP. Animal studies suggest that indirect ophthalmoscopy can cause retinal damage. ${ }^{23,24} \mathrm{Kirkness}^{25}$ has evaluated the retinal hazard posed by this instrument by calculation of the temperature rise resulting from light absorption in the retina, correlating retinal irradiance values with safety guidelines and comparing these figures with threshold values for retinal damage. These results suggest that the indirect

Table I. Mean irradiance for the two neonatal units surveyed. Measurements are given for the total irradiance in each of the wavelength bands, with standard deviations in parenthesis. Values are given separately for the high and low dependency regions of each unit.

Irradiance $\left(\mu \mathrm{W} / \mathrm{cm}^{2}\right)$

$400-500 \mathrm{~nm} 500-175 \mathrm{~nm} 400-700 \mathrm{~nm}$

\begin{tabular}{lccc}
\hline Unit A & & & \\
High dependency & 153.8 & 280.6 & 436.5 \\
& $(49.0)$ & $(83.6)$ & $(106.2)$ \\
Low dependency & 36.7 & 101.7 & 134.5 \\
& $(11.9)$ & $(28.7)$ & $(35.8)$ \\
Unit B & & & \\
High dependency & 145.3 & 314.1 & 529.2 \\
& $(28.9)$ & $(67.3)$ & $(134.1)$ \\
Low dependency & 34.6 & 132.6 & 165.2 \\
& $(9.8)$ & $(31.9)$ & $(43.3)$ \\
Mean & & & \\
High dependency & 149.5 & 297.1 & 482.8 \\
& $(38.9)$ & $(74.5)$ & $(120.2)$ \\
Low dependency & 35.6 & 117.2 & 149.8 \\
& $(10.3)$ & $(31.1)$ & $(39.6)$ \\
\hline
\end{tabular}

ophthalmoscope poses no threat of retinal damage for the adult, provided that exposure duration does not exceed 23-80 seconds per eye depending on the power of the supplementary lens used. Pupils remain unresponsive to light stimuli and dilated for $>18$ hours post-instillation of cyclopentolate $(0.5 \%)$. Perhaps therefore, the potential light hazard posed by the indirect ophthalmoscope per se is small compared with the effect of prolonged pupillary dilation.

The position of the baby within the unit and its head position relative to the mattress also influence the retinal light dose. The eye closer to the mattress is more likely to be closed. ${ }^{22,26}$ Due to shielding of the lower eye, by clothing, an arm, or the mattress, the lower eye or eyelids (eye closer to the mattress) receives a mean of $25 \%$ (range $0-78 \%$ ) of environment light, whereas for the upper eye or eyelids (eye away from the mattress) this mean value is $86 \%$ (range $57-100 \%$ ). ${ }^{27,28,29}$

\section{PHYSIOLOGICAL FACTORS}

Here we will consider the following topics: frequency and patterns of eyelid opening; transmission characteristics of the closed eyelid; transmission and absorption of light through the eye; pupillary diameter and retinal factors including area and photoreceptor distribution.

Frequency and patterns of eyelid opening have been examined in 50 neonates with a gestational age range of 24-35 weeks. ${ }^{22}$ Observations were made, over the 24 hour period to obtain a complete pattern of events. Mean eyelid closure was $74 \%$. When babies were grouped by gestational age, differences became apparent, babies of less than 26 weeks having their eyes shut for only 55\% of observations compared with $93 \%$ at 28 weeks. Trend analysis confirmed that eyelid closure reached a peak at 28 weeks. Neonates exposed to a day and night regimen opened their eyes significantly more than those exposed to continuous illumination.

When closed, the light transmission characteristics of the eyelids become important. Measurements of light transmission through the eyelid of adults, ${ }^{26}$ and preterm infants, measured in vivo, suggest that the eyelid acts as a predominantly red-pass filter. ${ }^{30}$ Peak transmission for the adult and neonatal eyelid was $18 \%$ and $22 \%$ respectively at $700 \mathrm{~nm}$ declining in both to $<5 \%$ tranmission below $480 \mathrm{~nm}$.

The passage of light through the ocular media depends on absorption, scatter and reflection by the ocular tissues. The ability of radiant energy to damage ocular tissues is largely determined by the spectral transmittance and/or absorbance properties of individual tissues. Both are probably wavelength dependent, and thus influence the spectral composition of "white" light absorbed by the photopigments. The spectral transmission properties of the ocular tissues taken as a whole were determined by Ludwigh and McCarthy ${ }^{31}$ working on freshly enucleated eyes. Since these data were obtained from elderly eyes (average age 62 years), the authors corrected their results for age-related changes in lens absorbance using data 
obtained from isolated lenses of younger eyes. Boettner and Wolter ${ }^{32}$ measured the spectral transmission properties of each component of the ocular media using nine eyes from subjects whose age ranged from four weeks to 75 years. These authors constructed a transmission curve light transmission through the eye of a young observer. The cornea transmits radiation from $295 \mathrm{~nm}$ in the ultraviolet to $2500 \mathrm{~nm}$ in the infra-red. Transmittance increases rapidly from $300 \mathrm{~nm}$ reaching about $70 \%$ at $380 \mathrm{~nm}$ and over $90 \%$ between 500 and $1300 \mathrm{~nm}\left(\right.$ see $^{33}$ ). The crystalline lens transmits radiation from 350 to $1900 \mathrm{~nm}$. The transmissivity of the lens decreases with age especially at the short wavelengths. ${ }^{33}$ Psychophysical determinations of lens absorption have depended largely on the study of aphakic observer responses and these investigations have shown that the visual sensitivity of an aphakic observer extends into the near UV, with little reduction in sensitivity between 400 and $320 \mathrm{~nm}$. This indicates that the lens acts as a shortwave cut-off filter for the eye. Said and Weale's ${ }^{34}$ values for the density of the lens are lower than those derived by phychophysical methods. The vitreous apparently causes some light scatter but Boettner and Wolter ${ }^{32}$ found that less than $10 \%$ of the incident light is absorbed.

Kishto ${ }^{35}$ produced evidence of variations in visual thresholds associated with screening by blood vessels, whilst Vos and Bouman ${ }^{36}$ estimated that light scatter in the retina constitutes some $30 \%$ of the total light scatter in the eye.

Thus the cornea, aqueous and lens normally filter out most radiation below $400 \mathrm{~nm} .{ }^{37}$ The ocular media of neonates are highly transmissive especially in the blue and ultra-violet regions of the spectrum, ${ }^{32,38,39}$ and the lens at this time transmits $>90 \%$ of light $\leqslant 420 \mathrm{~nm}^{40}$ Finally, light does not enter the eye exclusively through the pupil, as the sclera and choroid also transmit about $14 \%$, again predominantly at the red end of the spectrum. ${ }^{41,42}$

Retinal irradiance is influenced by pupil size. The time course for the development of the pupillary light reflex and its diameter before and after this event have been studied. ${ }^{43}$ The pupillary light reflex was absent in all neonates of less than 30 weeks gestation, gradually developing from this age, and by 34 weeks was present in all. These data are broadly similar to those reported by others, who state that pupils react to light around $30^{44}$ to 32 weeks gestational age. ${ }^{45,46}$ Before the onset of the pupil reflex, mean horizontal pupillary diameter was $3.46 \mathrm{~mm}$ compared with 3.02 $\mathrm{mm}$ after the reflex development. ${ }^{43}$

Before considering the retinal irradiance, or ocular light dose, it is appropriate to consider briefly retinal growth. Cones are present at the fovea by 12-14 weeks gestation. ${ }^{47}$ By the seventh month both rods and cones may be distinguished in the peripheral retina and there is no further increase in cell number after this time ${ }^{47,48}$ Retinal surface area increases two-fold between the sixth and ninth fetal months with a further 50\% increase occurring before the second postnatal year. ${ }^{49}$ Thus considerable redistribution of photoreceptors and other cellular elements must occur during this period. ${ }^{50,51}$
The adult human rod is some $2 \mu \mathrm{m}$ thick and $60 \mu \mathrm{m}$ long. Cones vary in shape and size depending on their position in the retina, becoming long and thin in the foveal region. Neonatal cone inner and outer segments are much shorter than their adult counterparts, measuring $8.7 \mu \mathrm{m}$ compared with $32 \mu \mathrm{m}$ respectively, ${ }^{52}$ and it is possible, that foveal cones of the preterm neonate trap photons inefficiently. ${ }^{53}$

Using the aforementioned data an estimate of the retinal irradiance received by a preterm neonate has been made. ${ }^{27,28}$ As shown in Figure 1 this declines as a function of increasing postmenstrual age. For example, the immature neonate of 29 weeks PMA receives $\sim 350 \mu \mathrm{W} / \mathrm{cm}^{2}$, a level similar to that known to cause cone damage in the macaque monkey. ${ }^{54}$

\section{THE ACTION OF LIGHT ON THE EYE}

Light is the essential stimulus for vision, and in addition to photoreceptor metabolism it may also affect other aspects of retinal metabolism, ${ }^{55}$ and induce retinal damage. Lightinduced free radical oxidation of rod outer segment membrane lipids has been proposed as one of the early signs of light damage. ${ }^{56,57,58}$ Any factor, such as light, will by increasing the production of free radicals thus raise the possibility of tissue damage. ${ }^{59}$

In the adult exposure to light increases retinal metabolic activity ${ }^{55}$ which shifts from aerobic to anaerobic. ${ }^{60}$ Retinal blood flow and oxygen consumption are both higher in the dark than light in the human, ${ }^{61,62}$ although Hill and House$\operatorname{man}^{63}$ recorded increased flow in some cats but decreased in others in response to dark exposure. Raised retinal oxygen tension has been measured in the light compared to the dark in the rabbit, ${ }^{64}$ confirming decreased metabolic activity under these conditions. Oxygen consumption across the cat retina in the light was only $60 \%$ of that in the dark. ${ }^{65}$

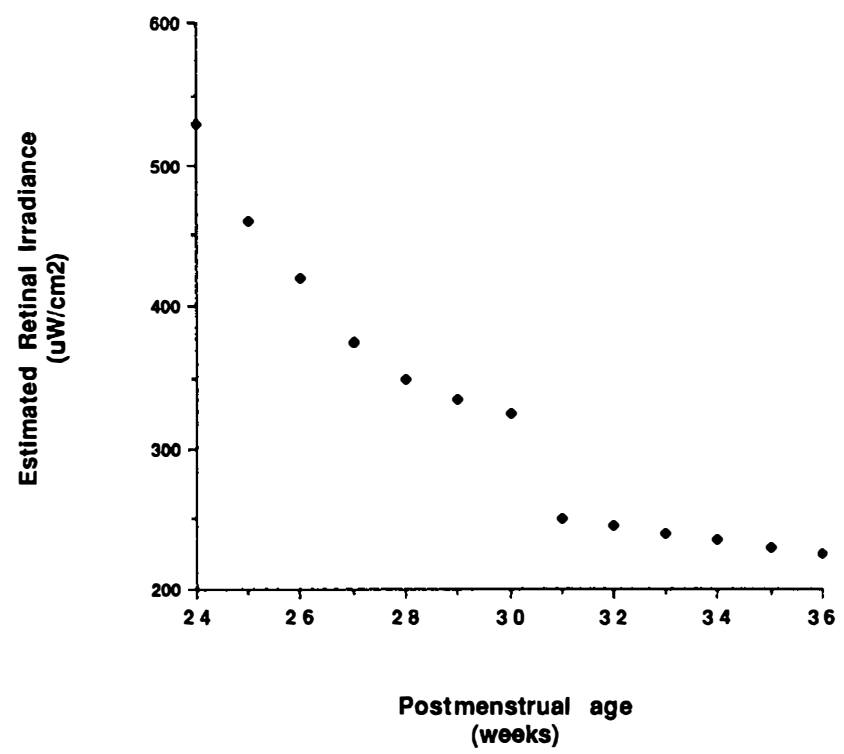

Fig 1. Estimated retinal irradiance $\left(\mu W / \mathrm{cm}^{2}\right)$, as a function of postmenstrual age. The reduction at 30-31 weeks PMA may partly be explained by the onset of the pupillary light reflex and also the move from a high to low dependency nursery. The latter are associated with lower luminance. 
Recently, Dorey and associates ${ }^{66}$ demonstrated that blue light inhibits the growth of retinal endothelial cells. These authors stated that since light or oxygen act synergistically with Dopa to inhibit endothelial cell growth; exposure to light or oxygen could exacerbate the potential for vascular damage. The levels of dopamine in the immature retina are about $1 / 20$ th of those in the adult $;{ }^{67}$ Hollyfield and associates, ${ }^{68}$ have suggested that the low dopamine concentrations at birth could be partly due to very low light levels in utero.

In the adult, under normal conditions, the intracellular content of both superoxide dismutase and peroxidases are sufficient to remove superoxide radicals and peroxides generated by oxidative metabolism. ${ }^{69}$ Slater and Riley ${ }^{59}$ suggested that the oxidant-antioxidant balance in the retina of a preterm neonate was critical because of the potential for light-induced auto-oxidative damage to the lipid membranes. In the following sub-sections we will consider some factors which may be involved in free radical scavenging in the immature human retina. ${ }^{70}$ We can find no information about the levels or activity of superoxide dismutase in the retina of the preterm neonate.

Vitamin C may aid Vitamin E regeneration ${ }^{69}$ and its level in the preterm retina exceeds adult levels by $35-50 \% .^{71}$ In contrast retinal Vitamin E levels in the preterm neonate are low (5-12\% of levels in mature tissue) particularly in the avascular regions. ${ }^{71}$ Vitamin E supplementation increases retinal tissue levels, particularly in those neonates of $>27$ weeks gestational age. ${ }^{71}$

Preterm infants are deficient in selenium. ${ }^{72}$ This trace element is an essential component of both glutathione-Stransferase and glutathione peroxidase, and both enzymes play a role in the prevention of autoxidative damage. ${ }^{70}$ No age-related changes in glutathione S-transferase activity have been detected $;^{71,73}$ however the specific activity of glutathione peroxidase is higher in preterm than mature retinae. $^{71}$

Paralleling photoreceptor differentiation, a space develops between the retinal pigment epithelium, photoreceptors and Müller cells. This sub-retinal space appears first in the central retina at 20 weeks gestational age and by 28 weeks it covers $75 \%$ of the retinal area. ${ }^{74}$ This space contains the inter-photoreceptor matrix of which interphotoreceptor binding protein (IRBP) is a major constituent. $^{75}$ This protein facilitates nutrient transport, including Vitamins $\mathrm{E}$ and $\mathrm{A}$, between the retinal pigment epithelium and the neural retina. ${ }^{76}$ Thus IRBP may have a role in protecting the retina from light damage (for example see ${ }^{76}$ ).

We will now consider physical and genetic factors which influence susceptibility to retinal light damage. In 1966, Noell and co-workers showed that light damage (photochemical) of the rat retina caused attenuation of electroretinogram (ERG) responses and photoreceptor cell degeneration. ${ }^{57}$ Today, it is known that the severity of damage is related to both the physical properties of the light such as its intensity, wavelength and duration of exposure. ${ }^{12,77}$ In the primate, abnormal continuous retinal illumination provided by virtually full-field fluorescent lamps can severely damage the retina. ${ }^{78}$ Human protective, behavioural patterns (blinking, gaze aversion etc) fortunately prevent the adult from staring for minutes, hours, or even days at banks of high intensity fluorescent lamps. If these are not present, photoreceptor damage will result as shown by Calkins et al., in the 1960s (discussed in ${ }^{78}$ ) and by Kitahara et al. ${ }^{79}$ Another consideration is the genetic species variation in light-damage susceptibility found amongst different strains of mice and rats. ${ }^{80,81,82}$ Retinal susceptibility to light damage increases with age in the albino rat, ${ }^{83,84}$ as does dark rearing before light exposure. ${ }^{85}$ Ocular melanin has a protective function, presumably by the screening and absorption of light. ${ }^{57,80,86}$ These effects are associated with increasing rhodopsin content of the photoreceptors. ${ }^{87}$ Although there is extensive characterisation of the factors mentioned above, little is known about the manner by which they exert their influence, partly due to an incomplete understanding of the development of metabolic function in the immature retina and the precise mechanisms of retinal light toxicity. ${ }^{88}$

\section{CLINICAL ASSOCIATIONS WITH LIGHT EXPOSURE}

Although the adverse or even beneficial effects of early light exposure to the developing human visual system are unknown, preterm babies are at risk of developing a variety of ocular problems in which early exposure to light has been implicated (for review see ${ }^{4}$ ).

Whether light-induced photoreceptor cone damage occurs in the human preterm infant is unknown, but cone dysfunction has been reported in children who received stray light from phototherapy as neonates, ${ }^{89}$ and low, but normal acuity has been noted in ex-premature children ${ }^{90,91}$ and teenagers. ${ }^{92}$ There is no evidence, however, for significantly accelerated visual development following preterm birth. ${ }^{4,93}$

The role of light in the pathogenesis of ROP has been debated for nearly 50 , years. ${ }^{4}$ Unfortunately, each of these studies can be criticised on the basis of their experimental design, and this important and topical question remains unanswered. Ricci and co-workers ${ }^{94}$ failed to demonstrate a role for light in oxygen-induced retinopathy in the rat; but their animals were exposed to 12 hour cycles of light and dark, a situation not analagous to lighting conditions in the NNU. We have recently reported an association between the location of the retinopathy at onset and the retinal light dose..$^{10,95}$ It is apparent (see previous sections) that due to large variations in the neonatal light environment, single light measurements at infrequent intervals are inadequate to estimate the total light dose received by an individual preterm baby. Therefore to investigate the relation between light exposure and ROP continuous monitoring of the light environment of each infant is required. With this aim in mind we have developed a portable monitor - the EyeLiDD — which enables light intensity (i.e. illuminance and irradiance) to be sampled at eight second intervals and an average intensity stored every ten 
minutes for periods exceeding 100 days. Data obtained with the EyeLiDD can be used to estimate either a total light dose received by each neonate, or to follow the patterns of light exposure over various time-periods.

Exposure to light may also have effects remote from the visual system. Melatonin has been implicated in the regulation of various neural and endocrine processes in vertebrates which are cued by the daily change in photoperiod, including the control of circadian rhythms and the modulation of photoreceptor renewal. ${ }^{96}$ It has been suggested that continuous exposure to bright light affects sleep states, ${ }^{97}$ hormonal biorhythms ${ }^{98}$ and may increase the frequency of patent ductus arteriosus. ${ }^{99,100}$ The absence of day and night cycling in the NNU may be a factor responsible for the delayed onset of periodicities and sleeping problems in preterm neonates. ${ }^{101}$ Exposure of human neonates to constant lighting reverses their normal diurnal variation in blood amino acid concentrations. ${ }^{72}$

To conclude, the baby born before term may spend days, weeks or months in an environment which is both bright and usually constantly lit. As estimates of the retinal light dose have only recently been attempted, the effects of this early exposure to light on the immature visual system and on the baby as a whole are poorly understood and require further study.

Judith Robinson was funded by the Royal National Institute for the Blind and is a Wellcome Trust Training Fellow.

Key words: Keywords: Light, Inf ant-preterm, Development, Retinopathy-of-prematurity, Retina.

\section{REFERENCES}

1. Weaver DR and Reppert SM: Direct in utero perception of light by the mammalian fetus. Dev Brain Res 1989, 47: $151-5$.

2. Mutch LMM: Epidemiology, perinatal mortality and morbidity. In Roberton NRC ed. Textbook of Pediatrics, Edinburgh: Churchill Livingsston 1986; 3-19.

3. Moseley MJ and Fielder AR: Open Letter: Light toxicity and the neonatal eye. Clin Vis Sci 1988, 3: 75-82.

4. Fielder AR, Foreman N, Moseley MJ, Robinson J: Prematurity and visual development. In Simons $K$ and Guyton DL eds. Infant Vision Research: Basic and Clinical Research. N.Y., Oxford University Press.

5. Terry TL: Extreme prematurity and fibroblastic overgrowth of persistent vascular sheath behind each crystalline lens I: Preliminary report. Am J Ophthalmol 1942, 25: $203-4$.

6. Locke JC and Reese AB: Retrolental Fibroplasia: The negative role of light, mydriatics and the ophthalmoscopic examination in its etiology. Arch Ophthalmol 1952, 48: 44-7.

7. Hepner WR, Krause AC, Davis ME: Retrolental fibroplasia and light. Paediatrics 1949, 3: 824-8.

8. Glass P, Avery GB, Kolinjavadi N, Subramanian S, Keys MP, Sostek AM and Friendly DS: Effect of bright light in the hospital nursery on the incidence of retinopathy of prematurity. $N$ Eng J Med 1985, 313: 401-4.

9. Ackerman B, Sherwonit E, Williams J: Reduced incidental light exposure: effect on the development of retinopathy of prematurity in low birth weight infants. Pediatrics 1989, 83: $958-62$.

10. Fielder AR, Robinson J, Shaw DE, Ng YK, Moseley MJ: Light and retinopathy of prematurity: does retinal location offer a clue? Pediatrics 1992, 89.

11. Lawwill T: Three major pathologic processes caused by light in the primate retina: a search for mechanisms. Trans Am Ophthalmol Soc, Rochester: Johnston Press 1982: xxx, 517-79.

12. Lanum $\mathrm{J}$ : The damaging effects of light on the retina. Empirical findings, theoretical and practical implications. Surv Ophthalmol 1978, 22: 221-49.

13. West SK: Who develops cataracts? Arch Ophthalmol 1991, 109: $196-8$.

14. MacLeod $P$ and Stern L: Natural variations in environment illumination in a newborn nursery. Pediatrics 1972, 50: 131-3.

15. Robinson J, Moseley MJ, Fielder AR: Illuminance of neonatal units. Arch Dis Child 1990, 65: 679-82.

16. Hamer RD, Dobson V, Mayer MJ: Absolute thresholds in human infants exposed to continuous illumination. Invest Ophthalmol Vis Sci 1984, 25: 381-8.

17. Robinson J and Fielder AR: Spectral characteristics of neonatal unit lighting. Invest Ophthalmol Vis Sci (suppl) 1991, 32: 1146.

18. Landry RJ, Scheidt PC, Hammond RW: Ambient light and phototherapy conditions of eight neonatal care units: A summary report. Pediatrics 1985 , 75: 434-6.

19. Porat R, Brodsky N, Hurt H: Effective eye shielding during phototherapy. Clin Pediatr 1988, 28: 199-200.

20. Chin KC, Moseley MJ, Bayliss SC: Light transmission of phototherapy eyeshields. Arch Dis Child 1987, 62: 970-1.

21. Robinson J, Moseley MJ, Fielder AR, Bayliss SC: Light transmission measurements and phototherapy eyepatches. Arch Dis Child 1991, 66: 59-61.

22. Robinson J, Moseley MJ, Thompson JR, Fielder AR: Eyelid opening in preterm neonates. Arch Dis Child 1989, 64: 943-8.

23. Friedman $\mathrm{E}$ and Kuwabara $\mathrm{T}$ : The retinal pigment epithelium IV: The damaging effects of radiant energy. Arch Ophthalmol 1968, 80: 265-79.

24. Tso MOM, Fine BS, Zimmerman LE: Photic maculopathy produced by the indirect ophthalmoscope. Am J Ophthalmol 1972, 73: 686-90.

25. Kirkness CM: Do ophthalmic instruments pose a hazard of light-induced damage to the eye? In Chronily-Dillon J, Rosen ES and Marshall J eds. Hazards of Light, Myths and Realities, Eye and Skin. Oxford: Pergamon Press 1986: 179-86.

26. Moseley MJ, Thompson JR, Levene MI, Fielder AR: Effects of nursery illumination on frequency of eyelid opening and state in preterm neonates. Early Hum Dev 1988, 18: $13-26$.

27. Robinson J, Moseley MJ, Fielder AR: Light and the eye of the preterm neonate. Invest Ophthalmol Vis Sci 1990, 31 Suppl: 119 .

28. Robinson J (1990) Light and the eye of the preterm neonate. $\mathrm{PhD}$ thesis, Birmingham University, United Kingdom.

29. Robinson J, Aulcott G, Moseley MJ, Fielder AR: Illumination at the eye of the preterm neonate (in preparation).

30. Robinson J, Bayliss SC, Fielder AR: Transmission of light across the adult and neonatal eyelid in vivo. Vision Res 1991, 31: 1837-40.

31. Ludwigh WE and McCarthy EF: Absorption of visible light by the refractive components of the human eye. Arch Ophthalmol 1938, 20: 37-51.

32. Boettner EA and Wolter JR: Transmission of the ocular media. Invest Ophthalmol 1962, 1: 766-83.

33. Weale RA: Biography of the Eye. Development, Growth, Age. London: H K Lewis and Co Ltd, 1982.

34. Said FS and Weale RA: The variation with age of the spectral transmissivity of the living human crystalline lens. Gerontologica 1959, 3: 731-3.

35. Kishto BM (1968) The photometric evaluation of flashing light sources in relation to their conspicuity. $\mathrm{PhD}$ Thesis, University of London. 
36. Vos JJ and Bouman MA: Contribution of the retina to entopic scatter. J Opt Soc Am 1964, 54: 95-100.

37. Dayhaw-Barker P and Barker FM: Photoeffects on the eye. J Toxicol-Cut Ocular Toxicol 1985, 4: 269-99.

38. Lerman S: Ocular phototoxicity. In Davidson SI and Fraunfelder FT eds. Recent Advances in Ophthalmology. Churchill-Livingstone 1985: 109-36.

39. Lerman S: Ocular phototoxicity. N Engl J Med 1988, 319: 1475-7.

40. Barker FM, Brainard GC, Dayhaw-Barker P: Transmittance of the human lens as a function of age. Invest Ophthalmol Vis Sci (Suppl) 1991, 32: 1083.

41. Kopeiko LG, Yu M, Koretskaya DI, Mitkokh O, Chentsova B: Spectral characteristics of eyeball coats. Vesten Oftalmol 1979, Pt. 1: 46-9.

42. van den Berg TJTP, de Waard PWT and IJspeert JK: Light transmission through the ocular coats and retinal straylight distribution. Invest Ophthalmol Vis Sci 1990, 31 Suppl: 412.

43. Robinson $\mathrm{J}$ and Fielder A: Pupillary diameter and reaction to light in preterm neonates. Arch Dis Child 1990, 65: 35-8.

44. Robinson RJ: Assessment of gestational age by neurological examination. Arch Dis Child 1966, 41: 437-47.

45. Isenberg SJ, Dang Y, Jotterand V: The pupils of term and preterm infants. Am J Ophthalmol 1989, 108: 75-9.

46. Isenberg SJ, Molarte A, Vazquez M: The fixed and dilated pupils of premature neonates. Am J Ophthalmol 1990, 110: 168-71.

47. Provis JM, van Driel D, Billson FA, Russell P: Development of the human retina: patterns of cell distribution and redistribution in the ganglion cell layer. J Comp Neurol 1985, 233: 429-51.

48. Horstein GP and Winkleman JE: Electrical activity of the retina in relation to histological differentiation in infants born prematurely and at full term. Vision Res 1962, 2: 269-76.

49. Robb RM: Increase in retinal surface area during infancy and childhood. J Pediatr Ophthalmol Strabismus 1982, 19: 16-20.

50. Packer O, Hendrickson AE, Curcio CA: Developmental redistribution of photoreceptors across the Macaca nemestrina (Pigtail Macaque) retina. J Comp Neurol 1990, 298: 472-93.

51. Packer O, Hendrickson AE, Curcio CA: Photoreceptor topography of the retina in the adult pigtail macaque (Macaca nemestrina). J Comp Neurol 1989, 288: 165-83.

52. Yuodelis $\mathrm{C}$ and Hendrickson A: A qualitative and quantitative analysis of the human fovea during development. Vision Res 1986, 26: 847-55.

53. Banks MS and Bennett PJ: Optical and photoreceptor immaturities limit the spatial and chromatic vision of human neonates. J Opt Soc Am A 1988, 5: 2059-79.

54. Sykes SM, Robison WG, Waxler M, Kuwabara T: Damage to the monkey retina by broad-spectrum fluorescent light. Invest Ophthalmol Vis Sci 1981, 20: 425-34.

55. Hansson H-A: A histochemical study of cellular reactions in rat retina transiently damaged by visible light. Exp Eye Res 1971, 12: 270-4.

56. Riley PA and Slater TF: Pathogenesis of retrolental fibroplasia. Lancet 1969, ii: 265.

57. Noel WK, Walker VS, Kang BS and Berman S: Retinal damage by light in rats. Invest Ophthalmol Vis Sci 1966, 5: 450-73.

58. Wiegand RD, Joel CD, Rapp LM, Nielsen JC, Maude MB, Anderson RE: Polyunsaturated fatty acids and vitamin $\mathrm{E}$ in rat rod outer segments during light damage. Invest Ophthalmol Vis Sci 1986, 27: 727-33.

59. Slater TF, Riley PA: Free-radical damage in retrolental fibroplasia. Lancet 1970, ii: 467.

60. Howeli WL, Rapp LM, Williams TP: Distribution of melan- osomes across the retinal pigment epithelium of a hooded rat: implications for light damage. Invest Ophthalmol Vis Sci 1982, 22: 139-44.

61. Feke GT, Zuckerman R, Green GJ, Weiter JJ: Response of human retinal blood flow to light and dark. Invest Ophthalmol Vis Sci 1983, 24: 136-41.

62. Riva CE, Grunwald JE, Petrig BL: Reactivity of the human retinal circulation to darkness: a laser Doppler velocimetry study. Invest Ophthalmol Vis Sci 1983, 24: 737-40.

63. Hill DW and Houseman J: Retinal blood flow in the cat following periods of light and darkness. Exp Eye Res 1985, 41: 219-25.

64. Stefansson E: Retinal oxygen tension is higher in light than dark. Pediatr Res 1988, 23: 5-8.

65. Haugh LM, Linsenmeir RA, Goldstick TK: Mathematical models of the spatial distribution of retinal oxygen tension and consumption, including changes upon illumination. Ann Biomed Eng 1990, 18: 19-36.

66. Dorey CK, Delori FC, Akeo, K: Growth of cultured RPE and endothelial cells is inhibited by blue light but not green or red light. Curr Eye Res 1990, 9: 549-59.

67. Frederick JM, Rayborn ME, Laties AM, Lam DMK, Hollyfield JG: Dopaminergic neurons in the human retina. $J$ Comp Neurol 1982, 210: 65-79.

68. Hollyfield JG, Frederick JM, Rayborn ME: Neurotransmitter properties of the newborn human retina. Invest Ophthalmol Vis Sci 1983, 24: 893-7.

69. Berman ER: Biochemistry of the Eye. New York: Plenum Press, 1991.

70. Katz ML and Robison WG Jr: Autoxidative damage to the retina: Potential role in retinopathy of prematurity. In Flynn JT and Phelps DL eds. Retinopathy of Prematurity: Problem and Challenge. New York: Alan R Liss Inc 1988: 237-48.

71. Nielsen JC, Naash MI, Anderson RE: The regional distribution of vitamins $\mathrm{E}$ and $\mathrm{C}$ in mature and premature human retinas. Invest Ophthalmol Vis Sci 1988, 29: 22-6.

72. Mantagos S, Moustogianni A, Varvarigou A, Frimas C: Effect of light on diurnal variation of blood amino acids in neonates. Biol Neonate 1989, 55: 97-103.

73. Naash MI, Nielsen JC, Anderson RE: Regional distribution of glutathione peroxidase and glutathione-S-transferase in adult and premature human retinas. Invest Ophthalmol Vis Sci 1988, 29: 149-52.

74. Johnson AT, Kretzer FL, Hittner HM, Glazebrook PA, Bridges CDB and Lam DMK: Development of the subretinal space in the preterm human eye: ultrastructure and immunmocytochemical studies. J Comp Neurol 1985, 233: 497-505.

75. Chader GJ: Interphotoreceptor retinoid-binding protein (IRBP): A model protein for molecular biological and clinically relevant studies. Invest Ophthalmol Vis Sci 1989, 30: 7-22.

76. Gonzalez-Fernandez F and Healy JI: Early expression of the gene for interphotoreceptor retinol-binding protein during photoreceptor differentiation suggests a critical role for the interphotoreceptor matrix in retinal development. $J$ Cell Biol 1990, 111: 2775-84.

77. Handelman GJ and Dratz EA: The role of antioxidants in the retina and retinal pigment epithelium and the nature of prooxidant-induced damage. Adv Free Radicals Biol Med 1986, 2: 1-89.

78. Sliney DH and Wolbarsht MW: Safety with lasers and other optical sources: A comprehensive handbook. New York: Plenum Press, 1980.

79. Kitahara K, Tamaki R, Hibino H, Oyama T, eds. Intense Blue Light. In, Verriest $\mathrm{G}$ ed colour vision deficiencies VIII Dordrecht, The Netherlands: Martinus Nijhoff/Dr W Junk, 1987. VIII: 21-9.

80. LaVail MM, Gorrin GM and Repaci MA: Strain differences 
in sensitivity to light-induced photoreceptor degeneration in albino mice. Curr Eye Res 1987, 6: 825-34.

81. LaVail MM, Gorrin GM, Repaci MA, Yasummura D eds. Light-induced retinal degeneration in albino mice and rats: Strain and species differences. Degenerative retinal disorders: Clinical and laboratory investigations. Alan R Liss Inc 1987: 439-54.

82. LaVail MM, Gorrin GM, Repaci MA, Thomas LA, Ginsberg HM: Genetic regulation of light damage to photoreceptors. Invest Ophthalmol Vis Sci 1987, 28: 1043-8.

83. O'Steen KW, Anderson KV, Shear CR: Photoreceptor degeneration in albino rats: dependency on age. Invest Ophthalmol Vis Sci 1974, 13: 334-9.

84. Malik S, Cohen D, Meyer E, Perlman I: Light damage in the developing retina of the albino rat: An electroretinographic study. Invest Ophthalmol Vis Sci 1986, 27: 164-97.

85. Noell WK and Albnrecht R: Irreversible effect of visible light on the retina: role of Vitamin A. Science 1971, 172: 76-9.

86. Rapp LM and Williams TP: The role of ocular pigmentation in protecting against light damage. Vision Res 1980, 20: 1127-31.

87. Penn JS and Thum LA: The rat as an animal model for retinopathy of prematurity. Prog Clin Exp Biol 1989, 314: $623-42$.

88. Kremers JJM and van Norren D: Two classes of photochemical damage in the retina. Laser Light Ophthalmol 1988, 2: 41-52.

89. Abramov I, Hainline L, Lemerise E, Brown AK: Changes in visual functions of children exposed as infants to prolonged illumination. J Am Optom Assoc 1985, 56: 614-9.

90. Getz L, Dobson V, Luna B: Full-term acuity card norms can be used for preterm children 0-3 years of age. Invest Ophthalmol Vis Sci (Suppl) 1991, 32: 962.
91. Sebris SL, Dobson V, Hartmann EE: Assessment and pre diction of visual acuity in 3- to 4-year old children born prior to term. Hum Neurobiol 1984, 3: 87-92.

92. Fledelius HC: Ophthalmic changes from $10-18$ years. A longitudinal study of sequels to low birthweight II visual acuity. Acta Ophthalmol 1981, 59: 64-70.

93. Fielder AR, Moseley MJ, Ng YK: The immature visual system and premature birth. In Whitelaw $\mathrm{A}$ and Cooke RWI, eds. The very immature infant. Br Med Bull 1988, 44: 1093-118.

94. Ricci B, Lepore D, Iossa M, Santo A, D’Urso M, Maggiano N: Effect of light on oxygen-induced retinopathy in the rat model. Doc Ophthalmol 1990, 74: 287-301.

95. Fielder AR, Shaw DE, Robinson J: ROP: Location-a clue to pathogenesis? Invest Ophthalmol Vis Sci 1990, 31 (Suppl): 119.

96. Dubocovich ML: Role of Melatonin in Retina. In Osborne NN and Chader GJ, eds. Progress in Retinal Research. Oxford: Pergamon Press, 1988: 129-151.

97. Glass P and Avery GB: Reply to light sleep and development (correspondence). Pediatrics 1987, 796: 1053-4.

98. Sisson TRC, Glauser SC, Glauser EM, Tasman W, Kuwabara T: Retinal changes produced by phototherapy. $J$ Pediatr 1970, 77: 221-7.

99. Rosenfeld W, Sadhjev S, Brunot V, Jhaven R, Zabaleta I, Evans HE: Phototherapy effect on the incidence of patent ductus arteriosus in premature infants: prevention with chest shielding. Pediatrics 1986, 78: 10-4.

100. Clyman RT and Rudolph AM: Patent Ductus Arteriosus. A new light on an old problem. Pediatr Res 1978, 12: 92-4.

101. Mann NP, Haddow R, Stokes L, Goodley S, Rutter N: Effect of night and day on preterm infants in a newborm nursery randomised trial. Br Med J 1986, 293: 1265-7. 